\title{
Determination of the platelet-derived growth factor BB by a competitive thrombin-linked aptamer-based Fluorometric assay
}

\author{
Limin Guo $^{1,2}$ • Qiang Zhao ${ }^{1,3}$
}

Received: 10 June 2016 / Accepted: 8 October 2016 / Published online: 18 October 2016

(C) Springer-Verlag Wien 2016

\begin{abstract}
The authors describe a competitive aptamer based assay for detection of the platelet-derived growth factor $\mathrm{BB}$ (PDGF-BB; used as a model protein). The assay is making use of thrombin (a serine protease) as an enzyme label for reporting signals. It is taking advantage of a highly selective aptamer and of the fairly specific enzymatic activity of thrombin in terms of cleaving artificial fluorogenic peptide substrates. In a first step, the surface of wells of microplates is coated with PDGF-BB. On addition of a sample containing PDGF-BB, free and bound PDGF-BB compete with each other for binding to a DNA probe that consists of an aptamer sequence for PDGF-BB and a 29-mer aptamer sequence for thrombin. After washing, thrombin is added and will attach to the DNA probe that bound to the PDGF-BB on the microplates. Following addition of a fluorogenic peptide substrate, the bound thrombin will catalyze the cleavage of the substrate to generate a fluorescent product whose fluorescence intensity is measured at excitation/emission wavelengths of $370 /$ $440 \mathrm{~nm}$. Fluorescence intensity decreases with increasing PDGF-BB concentration in the sample because less thrombin will bind to the PDGF-BB coated surface of the microplate.
\end{abstract}

Electronic supplementary material The online version of this article (doi:10.1007/s00604-016-1978-1) contains supplementary material, which is available to authorized users.

Qiang Zhao

qiangzhao@rcees.ac.cn

1 Institute of Environmental Science, College of Chemistry and Chemical Engineering, Shanxi University, Taiyuan 030006, China

2 School of Chinese Materia Medica, Shanxi University of Traditional Chinese Medicine, Taiyuan 030024, China

3 State Key Laboratory of Environmental Chemistry and Ecotoxicology, Research Center for Eco-Environmental Sciences, Chinese Academy of Sciences, Beijing 100085, China
Under optimal conditions, PDGF-BB can be quantified in the 0.125 to $3 \mathrm{nM}$ concentration range. This assay was successfully applied to the determination of PDGF-BB in spiked 100fold diluted human serum.

Keywords Aptasensor · Fluorescence · Enzyme label · Microplate assay $\cdot$ Microtiter plate $\cdot$ Fluorogenic enzyme substrate $\cdot$ Serine protease $\cdot$ DNA probe $\cdot$ Affinity binding . Dual functional probe $\cdot$ Displacement $\cdot$ Indirect analysis

\section{Introduction}

Aptamers have been involved in both diagnostic and therapeutic applications as a rival of antibodies. They are generated via systematic evolution of ligands by exponential enrichment (SELEX) technique [1, 2]. They possess several advantages over antibodies, such as simple synthesis, easy labeling, good stability, long shelf life, wide range of targets, and high binding affinity and selectivity. Therefore, various aptamer-based assays with detection formats including fluorescence, electrochemistry, chemiluminescence and colorimetry have been developed [3-5].

Thrombin is an important serine protease in blood [6]. It is also recognized as a biomarker for several diseases because thrombin is a critical mediator of coagulation, inflammation and angiogenesis [6]. Harnessing the analytical feature of aptamers, many sensitive and selective assays for thrombin have been developed by using aptamers for thrombin [6-8]. The widely used aptamers for thrombin include the 15-mer oligonucleotide (5'-GGT TGG TGT GGT TGG-3') [9] and the 29-mer oligonucleotide (5'-AGT CCG TGG TAG GGC AGG TTG GGG TGA CT-3') [10]. The 29-mer aptamer binds to thrombin with a higher affinity $\left(K_{\mathrm{d}} \approx 0.5 \mathrm{nM}\right)$ than the 15 -mer 
oligonucleotide ( $\left.K_{\mathrm{d}} \approx 100 \mathrm{nM}\right)$. Taking advantage of affinity capture and enzyme activity of thrombin in catalyzing cleavage of small peptide substrates, we developed aptamer capture-based assays for thrombin detection [11, 12]. Using thrombin as an enzyme label, recently we have reported a thrombin-linked aptamer assay (TLAA) for non-thrombin protein detection in a sandwich format [13], which relies on thrombin-binding aptamer, enzyme activity of thrombin, and affinity aptamer for protein targets. In the TLAA strategy, the target protein is sandwiched by the antibody on solid surface and a DNA probe that consists of an aptamer sequence for protein target and an aptamer sequence for thrombin. Then, thrombin binds to the sandwich complex through aptamer affinity binding. The attached thrombin catalyzes the cleavage of peptide substrate to detectable product to achieve the detection of target protein. This strategy converts protein target detection into the measurement of thrombin. This approach shows an interesting analytical application of thrombin and thrombin-binding aptamers to non-thrombin target analysis. However, this sandwich assay needs to use a pair of affinity ligands, one antibody and one aptamer. The success relies on the availability of the aptamer or antibody that binds to two distinct regions of the target.

Competition assay and displacement assay have the advantages of needing only one affinity ligand probe (i.e. single-site binding) and the reduction in the time required for the assay (only one capture incubation step). Competitive aptamer based assays have a wide application in chemical and biochemical analysis. Taking advantage of the affinity of aptamer to target, Baldrich et al. reported two displacement assays for the detection of thrombin [14]. In the first assay, biotinylated aptamer for thrombin is immobilized on streptavidin-coated plates, and enzyme-labeled thrombin is added and incubated. Then, unmodified thrombin is subsequently added to displace the enzyme-labeled thrombin. In the second assay, thrombin is immobilized on microtiter plates, and biotinylated aptamer is incubated, and then free thrombin is subsequently added to displace the aptamer from the complex. In the second assay, the detection of thrombin is achieved with addition of streptavidin-labeled horseradish peroxidase (HRP). Hansen et al. reported an electrochemical displacement aptamer assay for thrombin and lysozyme [15]. They immobilized the thiolated aptamers of thrombin and lysozyme onto the gold substrate simultaneously, followed with the binding of the $\mathrm{CdS}$ quantum-dot labeled with thrombin and the $\mathrm{PbS}$ quantum dot labeled with lysozyme. As the sample containing detection targets are added, the quantum-dot labeled proteins are displaced by the targets, and can be measured through electrochemical stripping detection. Wang et al. described a competition between immobilized tetracycline-BSA and free tetracycline for the binding to biotinylated aptamer, which was conjugated to the streptavidin-HRP to achieve the detection of tetracycline [16]. Cao et al. reported a competitive electrochemical assay for thrombin that based upon the competitive binding of thrombin and thrombin-gold nanoparticleglucose oxidase bioconjugate with the aptamer on the electrode [17].

Here we described a competitive format of thrombin-linked aptamer assay (TLAA) for the detection of platelet-derived growth factor BB (PDGF-BB), an important protein related with cell transformation and tumor growth and progression [18-20]. PDGF-BB was used here as a model protein to show the proof of concept of the competitive TLAA and to further expand the application of TLAA. The PDGF-BB was conjugated on the surface of microplates. Free PDGF-BB in solution competed with the PDGF-BB coated on the microplates to the binding of a DNA probe that contains a PDGF-BB aptamer sequence and a thrombin aptamer sequence. The DNA probe attached to the coated PDGF-BB then bound with thrombin through affinity interaction between aptamer and thrombin. Thrombin catalyzed the cleavage of a fluorogenic peptide substrate to a fluorescent product. The more free PDGF-BB was present in sample solution, the less DNA probe was attached onto PDGF-BB on the plates, and less thrombin was labeled on the microplate, causing decrease of fluorescence signals. This competitive TLAA enabled detection of PDGF-BB at $0.125 \mathrm{nM}$. This assay was also successfully applied to PDGF-BB analysis in complex sample matrix (e.g. diluted serum).

\section{Experimental}

\section{Reagents and materials}

The high-binding black 96-well NUNC Maxisorp plates (USA, http://www.thermofisher.com) were used. Recombinant human PDGF-BB, PDGF-AB and PDGF-AA were purchased from Invitrogen (USA, http://www. thermofisher.com). Bovine serum albumin (BSA), human immunoglobulin $\mathrm{G}(\mathrm{IgG})$ and lysozyme (Lys) were obtained from Sigma (USA, http://www.sigmaaldrich.com). Human $\alpha$ thrombin was bought from Haematologic Technologies Inc. (Essex Junction, VT) (http://www.haemtech.com). The fluorogenic peptide substrate of thrombin, N-p-tosyl-GlyPro-Arg-7-amido-4-methylcoumarin hydrochloride, was purchased from Sigma (USA, http://www.sigmaaldrich. com). The ultrapure water was obtained through a Purelab Ultra Elga Labwater system. A microplate reader (Varioskan Flash, Thermo Fisher Scientific, Inc) was used to record the fluorescence signals.

A DNA probe with the sequence, 5'-TAC TCA GGG CAC TGC AAG CAA TTG TGG TCC CAA TGG GCT GAG TA TTTTTT AGT CCG TGG TAG GGC AGG TTG GGG TGA CT-3', was synthesized and purified by Sangon Biotech (Shanghai, China, http://www.sangon.com). In the 
sequence, the boldface portion was the aptamer for PDGF$\mathrm{BB}$, and the underlined portion was the aptamer for thrombin [13]. A polyT sequence was used as a linker between these two aptamer sequences.

The following buffers were used in the experiments. Coating buffer consisted of $0.1 \mathrm{M} \mathrm{Na}_{2} \mathrm{CO}_{3}$ (pH 9.6). Blocking buffer was PBS $(137 \mathrm{mM} \mathrm{NaCl}, 2.7 \mathrm{mM} \mathrm{KCl}$, $\left.10 \mathrm{mM} \mathrm{Na} \mathrm{HPO}_{4}, 2 \mathrm{mM} \mathrm{KH} \mathrm{PO}_{4}, \mathrm{pH} 7.5\right)$ with $10 \mathrm{~g} \cdot \mathrm{L}^{-1}$ BSA. Assay buffer consisted of PBS, $1 \mathrm{mM} \mathrm{MgCl}_{2}$, and $4 \mathrm{~g} \cdot \mathrm{L}^{-1}$ BSA. Thrombin catalysis buffer was composed of $50 \mathrm{mM}$ Tris- $\mathrm{HCl}(\mathrm{pH} 8.5)$ and $1 \mathrm{M} \mathrm{NaCl}$. Two washing buffers were used, including buffer A (PBS and $0.1 \%$ Tween 20), buffer B (PBS, $1 \mathrm{mM} \mathrm{MgCl} 2$ and $0.1 \%$ Tween 20).

\section{Detection of PDGF-BB}

First, PDGF-BB coated microplate was prepared by the following procedure. $100 \mu \mathrm{L}$ of PDGF-BB $(15.5 \mathrm{nM})$ in coating buffer was added to the wells of microplate, and incubated overnight at $4{ }^{\circ} \mathrm{C}$. The wells were washed three times with $150 \mu \mathrm{L}$ of washing buffer A. $200 \mu \mathrm{L}$ of blocking buffer was added and incubated for $1 \mathrm{~h}$ at $37^{\circ} \mathrm{C}$ to block nonspecific binding sites of wells. After that, the wells were washed once with washing buffer A. Subsequently, $100 \mu \mathrm{L}$ of sample solution containing various concentrations of PDGF-BB and DNA probe $(0.035 \mathrm{nM})$ in assay buffer was added to the wells, and incubated for $30 \mathrm{~min}$ at $37^{\circ} \mathrm{C}$. After washing with buffer B, $100 \mu \mathrm{L}$ of thrombin $(10 \mathrm{nM})$ in assay buffer was added, and incubated for $30 \mathrm{~min}$ at $37^{\circ} \mathrm{C}$. The wells were then rinsed with buffer B for three times. $100 \mu \mathrm{L}$ of thrombin catalysis buffer containing fluorogenic peptide substrate $(0.06 \mathrm{mM})$ was added and incubated for $2 \mathrm{~h}$ at $37{ }^{\circ} \mathrm{C}$. Finally, the fluorescence was measured immediately by the microplate reader with excitation and emission at $370 \mathrm{~nm}$ and $440 \mathrm{~nm}$, respectively.

\section{Results and discussion}

\section{Detection principle of the competitive TLAA for PDGF-BB}

Figure 1 shows the principle of TLAA in a competitive format (competitive TLAA) for the detection of PDGF-BB. First, PDGF-BB coated microplate was prepared. Then, the PDGF-BB sample in solution and a DNA probe containing an aptamer for PDGF-BB and a 29-mer aptamer for thrombin were introduced into the PDGF-BB coated microplate. After washing, thrombin was added and bound with the DNA probe that attached to the PDGF-BB coated on microplate through the specific aptamer-thrombin interaction. Finally, thrombin catalyzed the cleavage of a fluorogenic peptide substrate into

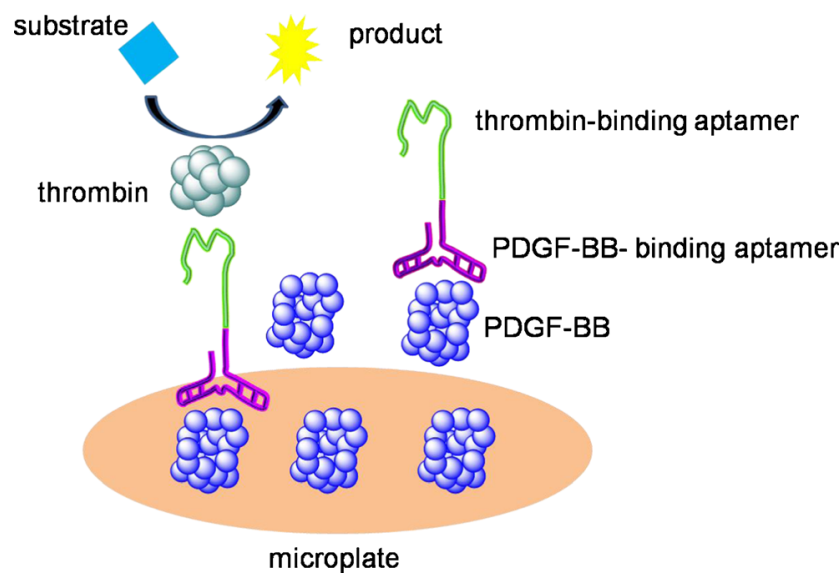

Fig. 1 Schemes of the competitive thrombin-linked aptamer assay (TLAA) for detection of PDGF-BB. Free PDGF-BB in solution and the PDGF-BB coated on the microplate competitively bind with a DNA probe containing the aptamer for PDGF-BB and the aptamer for thrombin. Thrombin binds with the DNA probe attached on the PDGF-BB coated on microplate and catalyzes the cleavage of fluorogenic peptide substrate to fluorescent product, generating signals. The increase of free PDGF-BB in solution leads to a decreased fluorescence signal

a detectable fluorescent product, generating fluorescence signal. The presence of PDGF-BB in sample solution causes decrease of fluorescence signal as the free PDGF-BB competed with the coated PDGF-BB on microplate for binding with the DNA probe. Thus, the detection of PDGF-BB in sample solution was achieved.

\section{Optimization of experimental conditions}

Figure 2 shows the obtained typical fluorescence signal in the absence of or in the presence of PDGF-BB sample in competitive TLAA. In the absence of PDGF-BB sample (blank), a strong fluorescence signal was observed, indicating the DNA probe was attached to the PDGF-BB that was coated on the

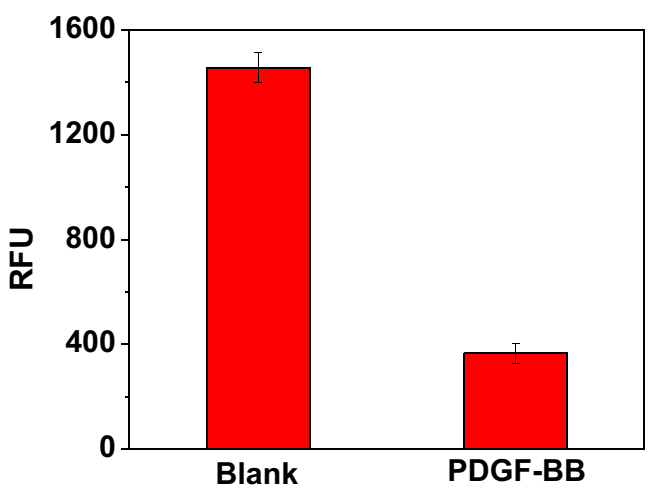

Fig. 2 Testing the feasibility of competitive TLAA for PDGF-BB detection. Blank sample and $3 \mathrm{nM}$ PDGF-BB were analyzed (relative fluorescence unit, RFU) Experimental conditions: $100 \mu \mathrm{L}$ of $15.5 \mathrm{nM}$ PDGFBB was used to prepare PDGF-BB coated microplate. $0.035 \mathrm{nM}$ DNA probe was applied in competition process. Thrombin at $10 \mathrm{nM}$ was used in thrombin-binding process 
microplates. In contrast, a greatly decreased signal was observed when $3 \mathrm{nM}$ PDGF-BB in sample solution was applied, suggesting that most of DNA probe bound to target PDGF-BB in solution instead of the coated PDGF-BB on microplate. Thus, the result shows that competitive TLAA is feasible for detection of PDGF-BB.

We then optimized the following parameters in experiments: (a) concentration of PDGF-BB in coating buffer for preparation of PDGF-BB coated microplate; (b) concentration of DNA probe; (c) concentration of thrombin. First, the concentration of PDGF-BB for the preparation of PDGF-BB coated microplate was optimized. More PDGF-BB was coated on the surface of wells of the microplate with increase of PDGF$\mathrm{BB}$ concentration, giving higher fluorescence signal of the blank sample in TLAA in the obtained PDGF-BB coated microplate. (shown in Fig. S1 in Supplementary Material). We chose PDGF-BB at $15.5 \mathrm{nM}$ in the coating buffer for preparation of the PDGF-BB coated microplate as a large signal was obtained at this condition. The efficiency of the competition process depends on the amount of the DNA probe used. The decrease of fluorescence signal caused by the added PDGF-BB in solution, $\triangle$ RFU, was obtained by subtracting the blank signal from the signal caused by added PDGF-BB. As shown in Fig. S2, the maximum absolute $\triangle$ RFU was obtained when $0.035 \mathrm{nM}$ DNA probe was applied. We used $0.035 \mathrm{nM}$ DNA probe in the assay. The concentration of thrombin also has great effect on the obtained absolute $\triangle$ RFU (shown in Fig. S3). $10 \mathrm{nM}$ of thrombin was used in the competitive TLAA as the maximum absolute $\triangle \mathrm{RFU}$ was obtained at this condition.

\section{Analytical performance of the competitive TLAA}

Figure 3 shows the change in $\triangle \mathrm{RFU}$ as a function of the concentration of PDGF-BB sample. With the increase of PDGF-BB in sample, the absolute $\triangle$ RFU increased. Fluorescence decrease is linear in the tested concentration

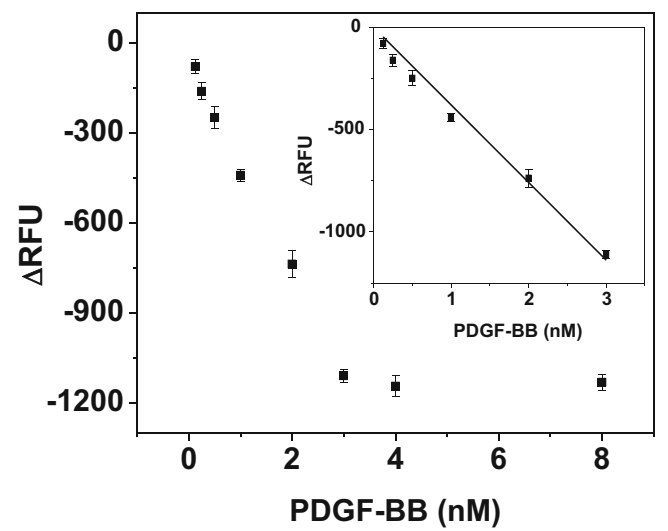

Fig. 3 The detection of PDGF-BB by the competitive TLAA in assay buffer. The inset shows the linear fitting curve for linear detection range range from $0.125 \mathrm{nM}$ to $3 \mathrm{nM}\left(\mathrm{y}=-379.4 \mathrm{x}, R^{2}=0.993\right.$, where $\mathrm{y}$ represented the $\triangle \mathrm{RFU}, \mathrm{x}$ represented the protein concentration). The detection limit was $0.125 \mathrm{nM}$. The sensitivity was compared with that from recently reported aptamer based assays for PDGF-BB (shown in Table 1) [21-35]. The sensitivity of our assay is comparable to that reported in some methods [21-27, 32, 34]. The use of amplification strategy through rolling circle amplification (RCA) or highly sensitive techniques can provide extremely high sensitivity for detection of PDGF-BB [28-31, 33, 35], better than our results. Compared with the sandwich TLAA assay [13], the competitive TLAA has lower sensitivity. Although many sensitive aptamer-based assay have been reported for the detection of PDGF-BB [28-31, 33, 35], here we demonstrate the competitive TLAA for protein detection is feasible by using the detection of PDGF-BB as an example. Our established method can be applied for the detection of PDGF-BB with the requirement of moderate sensitivity. Our entire assay procedure only requires one affinity ligand probe. Other detection methods for thrombin can be used in our assay formats though we applied fluorescence detection here [6].

\section{Specificity of the assay}

To evaluate the specificity of the competitive TLAA for PDGF-BB detection, we chose some other proteins including human immunoglobulin $\mathrm{G}(\mathrm{IgG})$, thrombin, and lysozyme (Lys). As shown in Fig. 4, the tested thrombin (20 nM), IgG $(100 \mathrm{nM})$, and lysozyme $(100 \mathrm{nM})$ did not cause remarkable decrease of fluorescence signal. The tested proteins did not interfere with the detection of PDGF-BB. This can be attributed to the inherent specific binding between the aptamer and its target protein.

In addition, A PDGF dimer composed of two different types of monomers ( $\mathrm{A}$ and $\mathrm{B}$ chains) occurs in three variants: PDGF-BB, PDGF-AB and PDGF-AA. The $\triangle$ RFU for $2 \mathrm{nM}$ PDGF-BB was about two times higher than that for $2 \mathrm{nM}$ PDGF-AB, and a negligible $\triangle \mathrm{RFU}$ was obtained in the presence of $2 \mathrm{nM}$ of PDGF-AA. The results can be explained by that the aptamer used here binds to these variants with different affinities [36, 37]. The signal caused by PDGF-AA was low because the aptamer did not bind to PDGF-A chain. PDGF-AB consists of both A and B chains, and the PDGF$B$ chain can bind to the aptamer. One PDGF-AB can only bind to one aptamer for PDGF-BB, while PDGF-BB can bind with two aptamers and has higher binding affinity [37]. Therefore, PDGF-AB can cause some signal change, but the signal change is smaller than that caused by PDGF-BB. The phenomenon is consistent with the previous reports [34, 35, 38]. The result clearly demonstrates that the competitive TLAA has a good selectivity for discrimination of PDGF-BB from other proteins. 
Table 1 An overview of some recently reported aptamer-based assays for PDGF-BB

\begin{tabular}{|c|c|c|c|}
\hline Methods and materials & Linear range & LOD & Ref. \\
\hline Colorimetry assay based on silver decahedral nanoparticles & $0.177-7.1 \mathrm{nM}$ & $177.5 \mathrm{pM}$ & 21 \\
\hline Fluorescence assay based on target-induced silver nanoclusters formation & $1-50 \mathrm{nM}$ & $370 \mathrm{pM}$ & 22 \\
\hline Fluorescence resonance energy transfer assay with graphene oxide surface & $0.167-1.167 \mathrm{nM}$ & $167 \mathrm{pM}$ & 23 \\
\hline Electrochemiluminescence assay with magnetic beads solid support & $0.1-1000 \mathrm{nM}$ & $80 \mathrm{pM}$ & 24 \\
\hline Electrochemistry assay with target binding-induced rolling circle amplification & $0.084-8.4 \mathrm{nM}$ & $63 \mathrm{pM}$ & 25 \\
\hline Chemiluminescence assay using gold nanoparticles through hydroxylamine amplification & $0.06-6 \mathrm{nM}$ & $60 \mathrm{pM}$ & 26 \\
\hline Fluorescence polarization assay based on multiple protein-DNA-protein structures & $0.1-6 \mathrm{nM}$ & $68 \mathrm{pM}$ & 27 \\
\hline Chemiluminescence assay based on exonuclease-assisted cascade autocatalytic recycling amplification & $1 \mathrm{pM}-10 \mathrm{nM}$ & $0.68 \mathrm{pM}$ & 28 \\
\hline Chemiluminescence assay based on rolling circle amplification and gold nanoparticles & $0.2-200 \mathrm{pM}$ & $0.06 \mathrm{pM}$ & 29 \\
\hline Electrochemiluminescence assay with glucose oxidase modified gold nanoparticles & $0.1-500 \mathrm{pM}$ & $0.017 \mathrm{pM}$ & 30 \\
\hline Electrochemistry assay with catalase functional DNA-platinum nanoparticles dendrimer & $0.05 \mathrm{pM}-35 \mathrm{nM}$ & $0.02 \mathrm{pM}$ & 31 \\
\hline Scanometric assay based on aptamer functionalized silver nanoparticles & $0.195-12.5 \mathrm{nM}$ & $195 \mathrm{pM}$ & 32 \\
\hline Electrochemistry assay with hyperbranched rolling circle amplification & $5-80 \mathrm{fM}$ & $1.6 \mathrm{fM}$ & 33 \\
\hline Affinity capillary electrophoresis with laser induced fluorescence detection & $0.5-50 \mathrm{nM}$ & $50 \mathrm{pM}$ & 34 \\
\hline Fluorescence assay based on three-dimensional carbon microarrays & $5 \mathrm{pM}-100 \mathrm{nM}$ & $5 \mathrm{pM}$ & 35 \\
\hline Sandwich thrombin-linked aptamer assay & $0.016-2 \mathrm{nM}$ & $16 \mathrm{pM}$ & 13 \\
\hline Fluorescence competitive thrombin-linked aptamer assay & $0.125-3 \mathrm{nM}$ & $125 \mathrm{pM}$ & This \\
\hline
\end{tabular}

To evaluate the applicability of this competitive TLAA for the target analysis in complex sample matrix, we investigated the detection performance of this assay for PDGF-BB in diluted serum samples. Under similar conditions, different concentrations of PDGF-BB spiked in the 100-fold diluted human serum were detected. As shown in Fig. S4, the detection limit was $0.125 \mathrm{nM}$, and a linear relationship between the $\triangle \mathrm{RFU}$ and concentration of PDGF-BB was achieved in the range from $0.125 \mathrm{nM}$ to $2 \mathrm{nM}\left(\mathrm{y}=-423.6 \mathrm{x}, R^{2}=0.983\right)$. The results indicate that the assay for detection of PDGF-BB in 100-fold diluted serum sample yields similar assay performance with that obtained in the binding buffer. It shows the assay can be applied in a complex sample matrix.

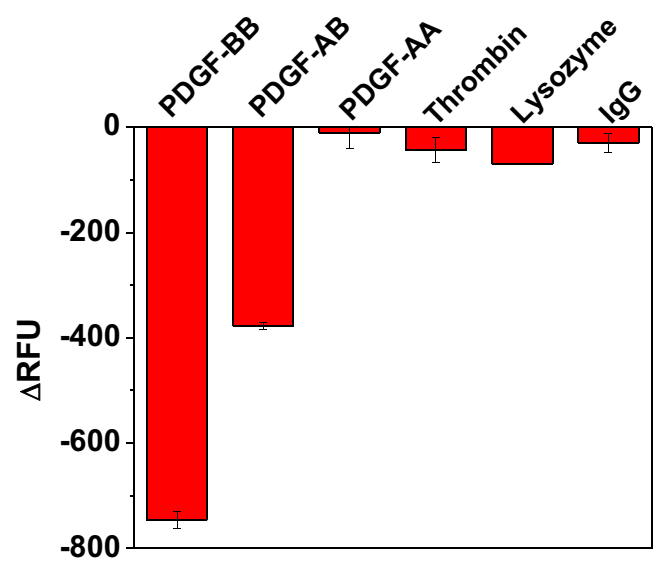

Fig. 4 Specificity test of the competitive TLAA for PDGF-BB detection by assessing PDGF-BB ( $2 \mathrm{nM})$ along with other proteins including PDGF-AB (2 nM), PDGF-AA ( $2 \mathrm{nM})$, thrombin (20 nM), lysozyme $(100 \mathrm{nM})$, and $\operatorname{IgG}(100 \mathrm{nM})$

\section{Conclusions}

In summary, we demonstrated a competitive thrombinlinked aptamer assay for the detection of PDGF-BB using thrombin as an enzyme label. PDGF-BB in solution and PDGF-BB coated on microplate competed for the affinity binding to a DNA probe that contained the aptamer for PDGF-BB and the aptamer for thrombin. Measurement of thrombin bound with the DNA probe allowed for final signal generation. This assay format only requires one affinity ligand for the target instead of two affinity ligands in sandwich assay. The sensitivity of the present assay is not high compared with some sensitive assays for PDGF-BB, further improvement is possible by combining sensitive techniques and amplification methods. The preparation of PDGF-BB coated microplate needs a long time, and improved coating process will help. When the PDGF-BB coated microplate is ready prior to use, the microplate-based assay allows for rapid sample handling and fast analysis, having potential for high throughput analysis. Though PDGF-BB is used as a model protein in our present assay, this assay format shows promise for detection of other proteins with thrombin as a label by using the corresponding aptamers sequence in the DNA probe used, and it can expand the analytical application of thrombin and aptamers.

Acknowledgments This work was supported by National Natural Science Foundation of China (Grant No. 21222503, 21435008, 21575153), Outstanding Youth Talents Program of Shanxi Province, and the Strategic Priority Research Program of the Chinese Academy of Sciences (XDB14030200). 
Compliance with ethical standards The author(s) declare that they have no competing interests.

\section{References}

1. Ellington AD, Szostak JW (1990) In vitro selection of RNA molecules that bind specific ligands. Nature 346:818-822. doi:10.1038 $1346818 \mathrm{a} 0$

2. Tuerk C, Gold L (1990) Systemic evolution of ligands by exponential enrichment: RNA ligands to bacteriophage T4 DNA polymerase. Science 249:505-510. doi:10.1126/science.2200121

3. Song SP, Wang SH, Li J, Zhao JL, Fan CH (2008) Aptamer-based biosensors. Trends Anal Chem 27:108-117. doi:10.1016/j. trac.2007.12.004

4. Li F, Zhang H, Wang Z, Newbigging AM, Reid MS, Li XF, Le XC (2015) Aptamers facilitating amplified detection of biomolecules. Anal Chem 87:274-292. doi:10.1021/ac5037236

5. Wu J, Zhu Y, Xue F, Mei Z, Yao L, Wang X, Zheng L, Liu J, Liu G, Peng C, Chen W (2014) Recent trends in SELEX technique and its application to food safety monitoring. Microchim Acta 181:479491. doi:10.1007/s00604-013-1156-7

6. Deng B, Lin YW, Wang C, Li F, Wang ZX, Zhang H, Li XF, Le XC (2014) Aptamer binding assays for proteins: the thrombin examplea review. Anal Chim Acta 837:1-15. doi:10.1016/j. aca.2014.04.055

7. Lee HJ, Kim BC, Oh MK, Kim J (2012) A sensitive and reliable detection of thrombin via enzyme-precipitate-coating-linked aptamer assay. Chem Commun 48:5971-5973. doi:10.1039/c2 cc30710c

8. Lin Z, Pan D, Hu T, Liu Z, Su X (2015) A near-infrared fluorescent bioassay for thrombin using aptamer-modified $\mathrm{CuInS}_{2}$ quantum dots. Microchim Acta 182:1933-1939. doi:10.1007/s00604-0151526-4

9. Bock LC, Griffin LC, Latham JA, Vermaas EH, Toole JJ (1992) Selection of single-stranded DNA molecules that bind and inhibit human thrombin. Nature 355:564-566. doi:10.1038/355564a0

10. Tasset DM, Kubik MF, Steiner W (1997) Oligonucleotide inhibitors of human thrombin that bind distinct epitopes. J Mol Biol 272:688 698. doi:10.1006/jmbi.1997.1275

11. Zhao Q, Li XF, Le XC (2011) Aptamer capturing of enzymes on magnetic beads to enhance assay specificity and sensitivity. Anal Chem 83:9234-9236. doi:10.1021/ac203063z

12. Zhao Q, Wang XF (2012) An aptamer-capture based chromogenic assay for thrombin. Biosens Bioelectron 34:232-237. doi:10.1016 j.bios.2012.02.009

13. Guo L, Zhao Q (2016) Thrombin-linked aptamer assay for detection of platelet derived growth factor BB on magnetic beads in a sandwich format. Talanta 158:159-164. doi:10.1016/j. talanta.2016.05.037

14. Baldrich E, Acero JL, Reekmans G, Laureyn W, O’Sullivan CK (2005) Displacement enzyme linked aptamer assay. Anal Chem 77: 4774-4784. doi:10.1021/ac0502450

15. Hansen JA, Wang J, Kawde AN, Xiang Y, Gothelf KV, Collins G (2006) Quantum-dot/aptamer-based ultrasensitive multi-analyte electrochemical biosensor. J Am Chem Soc 128:222-2229. doi:10.1021/ja060005h

16. Wang S, Yong W, Liu JH, Zhang LY, Chen QL, Dong YY (2014) Development of an indirect competitive assay- based aptasensor for highly sensitive detection of tetracycline residue in honey. Biosens Bioelectron 57:192-198. doi:10.1016/j.bios.2014.02.032

17. Cao JT, Zhang JJ, Gong Y, Ruan XJ, Liu YM, Chen YH, Ren SW (2015) A competitive photoelectrochemical aptasensor for thrombin detection based on the use of $\mathrm{TiO}_{2}$ electrode and glucose oxidase label. J Electroanal Chem 759:46-50. doi:10.1016/j. jelechem.2015.11.023

18. Pope DFB, Malpass TW, Foster DM, Ross R (1984) Plateletderived growth factor in vivo: levels, activity, and rate of clearance. Blood 64:458-469

19. Westermark B, Heldin CH (1993) Platelet-derived growth factor, structure, function and implications in normal and malignant cell growth. Acta Oncol 32:101-105. doi:10.3109 02841869309083897

20. Heldin CH (1992) Structural and functional studies on plateletderived growth factor. EMBO J 11:4251-4259

21. Li H, Zhu Y, Dong SY, Qiang WB, Sun L, Xu DK (2014) Fast functionalization of silver decahedral nanoparticles with aptamers for colorimetric detection of human platelet derived growth factorBB. Anal Chim Acta 829:48-53. doi:10.1016/j.aca.2014.04.034

22. Liu JJ, Song XR, Wang YW, Zheng AX, Chen GN, Yang HH (2012) Label-free and fluorescence turn-on aptasensor for protein detection via target-induced silver nanoclusters formation. Anal Chim Acta 749:70-74. doi:10.1016/j.aca.2012.09.002

23. Liang JF, Wei R, He S, Liu YK, Guo L, Li LD (2013) A highly sensitive and selective aptasensor based on graphene oxide fluorescence resonance energy transfer for the rapid determination of oncoprotein PDGF-BB. Analyst 138:1726-1732. doi:10.1039/c2 an36529d

24. Zhu DB, Zhou XM, Xing D (2010) A new kind of aptamer-base immunomagnetic electrochemiluminescence assay for quantitative detection of protein. Biosens Bioelectron 26:285-288. doi:10.1016 j.bios.2010.06.028

25. Wu ZS, Zhou H, Zhang SB, Shen GL, Yu RQ (2010) Electrochemical aptameric recognition system for a sensitive protein assay based on specific target binding-induced rolling circle amplification. Anal Chem 82:2282-2289. doi:10.1021/ac902400n

26. Wang P, Song YH, Zhao YJ, Fan AP (2013) Hydroxylamine amplified gold nanoparticle-based aptameric system for the highly selective and sensitive detection of platelet-derived growth factor. Talanta 103:392-397. doi:10.1016/j.talanta.2012.10.087

27. Jin X, Zhao JJ, Zhang LL, Huang Y, Zhao SL (2014) An enhanced fluorescence polarization strategy based on multiple protein-DNAprotein structures for sensitive detection of PDGF-BB. RSC Adv 4: 6850-6685. doi:10.1039/c3ra44092c

28. Bi S, Luo BY, Ye JY, Wang ZH (2014) Lable-free chemiluminescent aptasensor for platelet-derived growth factor detection based on exonuclease-assisted cascade autocatalytic recycling amplification. Biosens Bioelectron 62:208-231. doi:10.1016/j. bios.2014.06.057

29. Yao LY, Yu XQ, Zhao YJ, Fan AP (2015) An aptamer-based chemiluminescence method for ultrasensitive detection of platelet-derived growth factor by cascade amplification combining rolling circle amplification with hydroxylamine-enlarged gold nanoparticles. Anal Methods 7:8786-8792. doi:10.1039/c5ay01953b

30. Zhang JJ, Cao JT, Shi GF, Huang KJ, Liu YM, Ren SW (2015) A luminol electrochemiluminescence aptasensor based on glucose oxidase modified gold nanoparticles for measurement of plateletderived growth factor BB. Talanta 132:65-71. doi:10.1016/j. talanta.2014.08.058

31. Zhang J, Yuan YL, Shun BX, Chai YQ, Yuan R (2014) Amplified amperometric aptasensor for selective detection of protein using catalase-functional DNA-PtNPs dendrimer as a synergetic signal amplification label. Biosens Bioelectron 60:224-230. doi:10.1016 /j.bios.2014.04.024

32. Hu HT, Li H, Zhao YJ, Dong SY, Li W, Qiang WB, Xu DK (2014) Aptamer-functionalized silver nanoparticles for scanometric detection of platelet-derived growth factor-BB. Anal Chim Acta 812: 152-160. doi:10.1016/j.aca.2013.12.026

33. Wang QP, Zheng HY, Gao XY, Lin ZY, Chen GN (2013) A labelfree ultrasensitive electrochemical aptameric recognition system for 
protein assay based on hyperbranched rolling circle amplification. Chem Commun 49:11418-11420. doi:10.1039/c3cc46274a

34. Zhang H, Li XF, Le XC (2009) Differentiation and detection of PDGF isomers and their receptors by tunable aptamer capillary electrophoresis. Anal Chem 81:7795-7800. doi:10.1021 /ac901471w

35. Penmatsa V, Ruslinda AR, Beidaghi M, Kawarada H, Wang CL (2013) Platelet-derived growth factor oncoprotein detection using three-dimensional carbon microarrays. Biosens Bioelectron 39: 118-123. doi:10.1016/j.bios.2012.06.055
36. Huang CC, Chiu SH, Huang YF, Chang HT (2007) Aptamerfunctionalized gold nanoparticles for turn-on light switch detection of platelet-derived growth factor. Anal Chem 79:4798-4804. doi:10.1021/ac0707075

37. Green LS, Jellinek D, Jenison R, Ostman A, Heldin CH, Janjic N (1996) Inhibitory DNA ligands to platelet-derived growth factor Bchain. Biochemistry 35:14413-14424. doi:10.1021/bi961544+

38. Fang XH, Cao ZH, Beck T, Tan WH (2001) Molecular aptamer for real-time oncoprotein platelet-derived growth factor monitoring by fluorescence anisotropy. Anal Chem 73:5752-5757. doi:10.1021 /ac010703e 